\title{
Improving HIV/AIDS Knowledge Management Using EHRs
}

\author{
Erik D. Malmberg ${ }^{1}$, Thao M. Phan ${ }^{2}$, Glynn Harmon ${ }^{1}$, Richard F. Nauert ${ }^{3}$ \\ ${ }^{1}$ School of Information, The University of Texas at Austin \\ ${ }^{2}$ School of Public Health, The University of Texas Health Science Center at Houston \\ ${ }^{3}$ School of Health Administration, Texas State University-San Marcos
}

\begin{abstract}
Background: A primary goal for the development of EHRs and EHR-related technologies should be to facilitate greater knowledge management for improving individual and community health outcomes associated with HIV / AIDS. Most of the current developments of EHR have focused on providing data for research, patient care and prioritization of healthcare provider resources in other areas. More attention should be paid to using information from EHRs to assist local, state, national, and international entities engaged in HIV / AIDS care, research and prevention strategies. Unfortunately the technology and standards for HIV-specific reporting modules are still being developed.
\end{abstract}

Methods: A literature search and review supplemented by the author's own experiences with electronic health records and HIV / AIDS prevention strategies will be used. This data was used to identify both opportunities and challenges for improving public health informatics primarily through the use of latest innovations in EHRs. Qualitative analysis and suggestions are offered for how EHRs can support knowledge management and prevention strategies associated with HIV infection.

Results: EHR information, including demographics, medical history, medication and allergies, immunization status, and other vital statistics can help public health practitioners to more quickly identify at-risk populations or environments; allocate scarce resources in the most efficient way; share information about successful, evidenced-based prevention strategies; and increase longevity and quality of life.

Conclusion: Local, state, and federal entities need to work more collaboratively with NGOs, community-based organizations, and the private sector to eliminate barriers to implementation including cost, interoperability, accessibility, and information security.

Key Words: Usability of Health Information, Information Technology, Health Promotion / Disease Prevention

MeSH Headings: HIV, Acquired Immunodeficiency Syndrome, Public Health Informatics, Electronic Health Records, Knowledge Management 


\section{Introduction}

There has been considerable discussion at the local, state, national and international level about the benefits and challenges associated with electronic health records (EHRs). Public health information practitioners play an important role in helping control the HIV/AIDS epidemic by working with community, state, national, and international partners in surveillance, research, and prevention and evaluation activities. The Centers for Disease Control and Prevention (CDC) "estimates that about 1.1 million Americans are living with HIV, and that $21 \%$ of these persons do not know they are infected" [1]. Improved information gathering is essential to improving treatment, care, and support for HIV-infected persons as well as building the resources and infrastructure for prevention efforts in the United States and globally. "HIV treatment and research generally carry federal, state, and/or local government reporting obligations, particularly in programs funded by the Ryan White Comprehensive AIDS Resources Emergency (CARE) Act" [2]. Support should continue for the creation of bi-directional EHR systems (or add-on modules) in which HIV/AIDS information can be entered as well as accessed and utilized by public health information practitioners.

\section{HIV / AIDS Crisis in America}

HIV stands for the human immunodeficiency virus. HIV is a serious medical condition that damages a person's body by destroying blood cells that help the body fight diseases. HIV is spread primarily by:

- Not using a condom when having sex with a person who has HIV.

- Having multiple sex partners or the presence of other sexually transmitted diseases (STDs) can increase the risk of infection during sex. Unprotected oral sex can also be a risk for HIV transmission, but it is a much lower risk than anal or vaginal sex.

- Sharing needles, syringes, rinse water, or other equipment used to prepare illicit drugs for injection.

- Being born to an infected mother - HIV can be passed from mother to child during pregnancy, birth, or breast-feeding [3].

When certain conditions are met, this virus can lead to acquired immune deficiency syndrome, or AIDS.

It is estimated that more than one million people are living with HIV in the United States and that more than half a million have died after developing AIDS [4]. Yet the CDC reports that there are only about 680,000 cases as of 2008 [5]. This discrepancy is due in part to the lack of:

- adoption of confidential name-based reporting of HIV diagnoses in all 50 states;

- inclusion of anonymous tests, including home tests, in case reports; and

- diagnoses of HIV infection or person's awareness that they are infected.

"HIV statistics reported in the USA are currently only available for 40 states and five U.S. dependent areas with confidential name-based HIV infection reporting (since at least January 
2006). AIDS statistics include all 50 states, the District of Columbia and five U.S. dependent areas" [6].

Globally, in 2008 there were 33.4 million people living with HIV, and 2.7 million newly infected cases [7]. In the past 30 years, HIV/AIDS pandemic has caused 60 million infections and 30 million deaths [8]. It is the sixth leading cause of death in the world and is therefore one of the major public health problems [9]. Public health is playing a major role in its attempts to control and eradicate this disease.

According to the CDC, the earliest known case of HIV infection occurred in an adult male born and living in the Congo in 1959. Before the virus was identified in 1983, most documentation was based on diagnoses of opportunistic infections not found in health immune systems. It was not until 1999 that a group of researchers determined that a subspecies of chimpanzees native to west equatorial Africa were the original source of the virus. Tracking of AIDS cases began in 1982 in the United States.

By 1983 public health practitioners began using the term "acquired immunodeficiency syndrome," or AIDS, to describe the occurrences of opportunistic infections and even today the lay public continue to view these terms interchangeably (see Table 1). This was also the case

Table 1. Acquired Immunodeficiency Syndrome

Acquired - means that the disease is not hereditary but develops after birth from contact with a disease-causing agent (in this case, HIV).

Immunodeficiency - means that the disease is characterized by a weakening of the immune system.

Syndrome - refers to a group of symptoms that indicate or characterize a disease. In the case of AIDS, this can include the development of certain infections and/or cancers, as well as a decrease in the number of certain specific blood cells, called CD4+ T cells, which are crucial to helping the body fight disease.

because people infected with HIV would be diagnosed with AIDS in just a few years. Advances in research have led to increases in longevity and quality of life. "Since the beginning of the epidemic, an estimated 617,025 people with AIDS have died in the U.S." [10].

The CDC works with other federal agencies, state and local health departments, nongovernmental organizations (NGOs), community-based organizations, and the private sector to reduce the spread of HIV through

- Behavioral interventions;

- Educational interventions;

- Policy interventions;

- HIV testing;

- Linkages to treatment and care; and 
- Collection of data about transmission rates, incidence, testing behaviors [11] (CDC, 2012).

While these are important parts of dealing with the HIV epidemic, a lack of coordination and effective communication, inability to access and utilize information rapidly, and inconsistency in the execution of prevention strategies can negatively impact efforts to curb the spread of HIV infections in the United States. Electronic health records (EHRs) and innovations in knowledge management will be a critical component for sustained success in prevention efforts and patient care associated with HIV/AIDS.

\section{Knowledge Management in Public Health}

Most public health organizations face common challenges for managing information effectively. These efforts can be compounded even further when dealing with HIV / AIDS related health issues. The lack of standardized reporting procedures, exclusion of anonymous and home test from reports, and challenges in diagnoses primarily due to patient unawareness at the state and national level is troublesome. For approximately the past eight to ten years, public health officials have been increasingly interested in new knowledge management solutions. Knowledge management can generally be described as a process of organizing and analyzing information to make it understandable and applicable to problem solving or decision making. "Key reasons for this interest include the following: capturing knowledge to ensure public health preparedness, managing information more effectively, enabling public health professionals to work collaboratively in a virtual environment, and improving effectiveness in the face of dwindling resources" [12]. The challenge is that public health officials may fail to understand that effective knowledge management requires more than just developing policies and standards procedures. It requires commitment of capital and human resources, constant communication with a wide variety of constituencies, supportive leadership, buy-in public health officials at all levels, and technology.

The sheer volume of information that is produced at local, state, national, and international levels provides an impetus for using technology for better knowledge management. Reporting of HIV/AIDS cases is required at almost every level. However, there is also the challenge that ten states are still not able to effectively report HIV infection rates. A key question for those entities that are reporting information is whether this knowledge is being put to the best use.

The vast amounts of knowledge created every day also raise concerns about information quality. Developing successful public health initiatives and practices requires reliance upon quality evidence-based data. Knowledge management can help public health officials to organize and classify knowledge with greater confidence.

Another challenge associated with knowledge in public health is lack of consistency in format. Knowledge can come in many combinations including paper v. born-digital, image v. text, and text $\mathrm{v}$. audio. There can also be other differences in what information was collected and for what purpose. Lack of standardization also makes it more difficult for systems at various levels local, state, national, or international - to communicate with each other and promote greater 
sharing. A knowledge management system helps create a controlled vocabulary, ease of access and standard processes that eliminate waste.

Finally public health officials frequently express reservations about embracing knowledge management because of technology. Using information technology has risks associated with information security. This can be of particular concern when it comes to patient privacy and confidentiality. Great care must be taken and every effort made to reduce or eliminate security risks associated with public health knowledge management systems.

\section{Using Electronic Health Records}

An electronic health record (EHR) is generally defined as a systematic collection of electronic health information about individual patients or populations [13]. Electronic medical records (EMRs) and personal health records (PHRs) are important subsets of this overarching term. EHRs may include a range of data, including demographics, medical history, medication and allergies, immunization status, laboratory test results, radiology images, vital signs, personal stats like age and weight, and billing information. "The EHRs is a pivotal instrument in integrating clinical and public health data systems so public health authorities will have reliable, real-time data to support health policy decisions for better and safer care" [14].

The Department of Health and Human Services (DHHS) has developed a knowledge management model with a vision "to build a National Health Information Network (NHIN) of regional health information organizations (RHIO) and exchanges (RHIE). The RHIO and RHIE would in turn be formed of health care providers (HCPs) integrated via electronic health record systems (EHRS) to improve patient safety and deliver quality care" [15]. Public health knowledge management and consequently, treatment, care, and prevention stand at a threshold for exciting innovations as a result of the automation of in-patient and out-patient clinical data collected via EHRs. "Virco Lab, an independently operated biotechnology and diagnostics software subsidiary of pharmaceutical manufacturer Johnson \& Johnson, has released what may be the first electronic health records (EHR) system both optimized for HIV and AIDS care and certified to federal Meaningful Use standards" [16]. Efforts must continue towards the development of holistic EHR systems and/or add-on modules specifically for HIV/AIDS information with bi-directional or multi-directional communication features.

Electronic Health Records (EHRs) are not without their concerns or challenges. One of the major issues associated with use of EHRs, particularly given the structure of the United States health care system, is the cost to develop and implement. Healthcare providers and practitioners need the necessary hardware and software as well as the training for how to use it effectively. While there may be greater savings and efficiencies over time, these components have considerable startup costs. In the current economic climate, state and federal governments are being asked to prioritize resources in other areas. In addition, the political climate is such that efforts are being made to continue a decentralized approach to healthcare in the United States.

Another challenge that public health officials face in developing and using EHRs is accessibility and software quality. Healthcare reform in the U.S. has brought increased competition from within the marketplace for EHR systems. Each developer attempts to focus on a variety of 
aspects including design, content, and accessibility with varying degrees of success. While various systems that adopt the federal Meaningful Use standards will be able to communicate with each other, the interface for the users will still vary to some degree. The current lack of standardization both in terms of interface and interoperability continue to result in low adoption rates of EHRs among public health practitioners.

A third major challenge towards full adoption of an EHR, especially for HIV/AIDS related information, is security and privacy issues. "Threats to health care information can be categorized under three headings:

- Human threats, such as employees or hackers.

- Natural and environmental threats, such as earthquakes, hurricanes and fires.

- Technology failures, such as a system crashing.

These threats can either be internal, external, intentional and unintentional" [17]. While there are federal and state laws preventing discrimination on the basis of HIV/AIDS status, public release of EHR either intentionally or accidentally can have serious repercussions including loss of employment, health insurance coverage, or relationships. Both patients and public health officials remain concerned about how to reduce or eliminate these security and privacy risks. While an EHR definitely has its advantages over a paper health record, there still needs to be considerations about archiving practices and recoverability in the event of natural or man-made disasters.

Given the multiple benefits and costs of EHRs and the complexities and difficulties related to their adoption and implementation, the US and other countries have mandated the phased adoption of EHRs within their respective jurisdictions. In the US several programs (e.g., the American Investment and Recovery Act and the HIGHTECH Act) call for the phased adoption of EHRs over the next several years among many health care organizations [18].

\section{Conclusion}

The EHR will be a critical tool for public health officials to improve the treatment, care, and prevention of HIV infections and AIDS diagnoses. EHR information, including demographics, medical history, medication and allergies, immunization status, and other vital statistics can help public health practitioners to more quickly identify at-risk populations or environments; allocate scarce resources in the most efficient way; share information about successful, evidenced-based prevention strategies; and increase longevity and quality of life. "When the components of knowledge management - governance, content, process, and technology - are identified and addressed, organizations can begin to set a course that creates a significant asset from scattered, siloed stores if information" [19]. Local, state, and federal entities need to work more collaboratively with NGOs, community based organizations, and the private sector to eliminate barriers to implementation including cost, interoperability, accessibility, and information security. 


\section{Limitations}

The items listed above have been derived empirically and represent a broad picture of the challenges associated with developing a bidirectional public health knowledge management system. Undoubtedly there are other issues that may be equally significant and deserve recognition and attention. Although all stakeholders desire robust knowledge management, development of successful infrastructure remains an issue in countries far more advanced in their use health information technology and EHRs (UK, New Zealand) than the United States [20]. Adoption of EHRs in the United States remains a work in progress with the CDC reporting that $55 \%$ of physicians in office-based practices were using an EHR in some fashion in 2011 [21]. Our discussion of a bi-directional flow of information to communicate important HIV/AIDS information is consistent with federal expectations for HIT over a five-year period, if all the challenges can be surmounted including development of secure health information exchanges.

\section{Conflicts of Interest}

The authors declare that they have no conflicts of interests.

\section{Corresponding Author}

Erik D. Malmberg JD, PhD

Master's Degree Candidate

School of Information

The University of Texas at Austin

Austin, TX

Email: malmberged@utexas.edu

\section{References}

1. Centers for Disease Control and Prevention (2012). HIV/AIDS, II 1. Retrieved March 19, 2012, from http://www.cdc.gov/hiv/.

2. Versel, Neil (2011). Electronic Health Record Eases HIV, AIDS Reporting. InformationWeek. 3. Centers for Disease Control and Prevention (2012). HIV/AIDS Basics. Retrieved March 21, 2012, from http://www.cdc.gov/hiv/resources/qa/definitions.htm

4. Avert (2011). United States HIV \& AIDS Statistics Summary. Retrieved April 3, 2012, from http://www.avert.org/usa-statistics.htm.

5. Centers for Disease Control and Prevention (2012). HIV/AIDS. Retrieved March 19, 2012, from http://www.cdc.gov/hiv/.

6. Avert (2011). United States HIV \& AIDS Statistics Summary. Retrieved April 3, 2012, from http://www.avert.org/usa-statistics.htm.

7. UNAIDS (2009). AIDS Epidemic Update: December 2009 (Online). Accessed on May 9, 2012 from

http://www.unaids.org/en/media/unaids/contentassets/dataimport/pub/report/2009/jc1700_epi_up date_2009_en.pdf 
8. Hammer, S. M. (2011). Antiretroviral treatment as prevention. The New England Journal of Medicine, 365(6), 561-562.

9. World Health Organization (June, 2011). The Top 10 Causes of Death (Online). Accessed on May 9, 2012 from http://www.who.int/mediacentre/factsheets/fs310/en/index.html

10. Avert (2011). United States HIV \& AIDS Statistics Summary. Retrieved April 3, 2012, from http://www.avert.org/usa-statistics.htm.

11. Centers for Disease Control and Prevention (2012). HIV/AIDS. Retrieved March 19, 2012, from http://www.cdc.gov/hiv/.

12. Liebowitz, Jay (2009). Knowledge Management in Public Health [electronic resource]. Hoboken: CRC Press.

13. Wikipedia (2012). Electronic Health Records. Retrieved May 1, 2012, from http://en.wikipedia.org/wiki/Electronic_health_record.

14. Orlova, Anna O., Dunnagan, Mark Dunnagan, Finitzo, Terese, et al. (2005). An Electronic Health Record - Public Health (EHR-PH) System Prototype for Interoperability in $21^{\text {st }}$ Century Healthcare Systems. AMIA Annual Symposium Proceedings. Retrieved April 15, 2012, from http://www.ncbi.nlm.nih.gov/pmc/articles/PMC1560434/.

15. Orlova, Anna O., Dunnagan, Mark Dunnagan, Finitzo, Terese, et al. (2005). An Electronic Health Record - Public Health (EHR-PH) System Prototype for Interoperability in $21^{\text {st }}$ Century Healthcare Systems. AMIA Annual Symposium Proceedings. Retrieved April 15, 2012, from http://www.ncbi.nlm.nih.gov/pmc/articles/PMC1560434/.

16. Versel, Neil (2011). Electronic Health Record Eases HIV, AIDS Reporting. Information Week. Retrieved April 11, 2012, from http://www.informationweek.com/news/healthcare/EMR/232300871.

17. Wikipedia (2012). Electronic Health Records. Retrieved May 1, 2012, from http://en.wikipedia.org/wiki/Electronic health_record.

18. Hoyt, R. E. and others (2012). Health Informatics: Practical Guide for Healthcare and Information Technology Professionals. Raleigh, NC: LuLu.com.

19. Liebowitz, Jay (2009). Knowledge Management in Public Health [electronic resource]. Hoboken: CRC Press.

20. Neame, Roderick (2012). Design Principles in the Development of (Public) Health Information Intrastructures. Online Journal of Public Health Informatics. Retrieved August 17, 2012, from http://ojphi.org/htbin/cgiwrap/bin/ojs/index.php/ojphi/article/view/4022/3222.

21. Jamoom E, Beatty P, Bercovitz A, et al. (2012). Physician Adoption of Electronic Health Record Systems: United States, 2011. Retrieved September 15, 2012, from http://www.cdc.gov/nchs/data/databriefs/db98.htm. 